\title{
Can a Surgical Technique Be a Risk for Post-tonsillectomy Haemorrhage? Our Point of View
}

\author{
Sergio Motta, MD'; Domenico Testa, MD, PhD²*; Brillante Ferrillo, MD2; \\ Eva Aurora Massimilla, MD²; Roberto Varriale, MD²; Teresa Barrella, MD; \\ Giovanni Motta, MD2; Gaetano Motta, MD²
}

\begin{abstract}
'Department of Neurosciences, Institute of Otorhinolaryngology, University of Naples "Federico II", Italy
${ }^{2}$ Department of Anesthesiologic, Surgical and Emergency Sciences, Head and Neck Surgery Unit, University of Campania "Luigi Vanvitelli", Italy

3Department of Political Science, University of Naples "Federico II", Italy
\end{abstract}

\begin{abstract}
Objectives: Controversies have recently arisen regarding post-operative haemorrhagic complications in relation to the surgical procedures adopted for tonsillectomy. The authors set out to verify the relationship between surgical techniques and post-operative haemorrhage based on the analysis of data derived from multi-centric studies.

Materials and Methods: Multi-centric studies published between 2000 and 2015 were selected. The data relevant to haemorrhagic complications were elaborated by ANOVA test.

Results: Eight multi-centric studies were analysed. The mean frequency of post-tonsillectomy haemorrhage was: $1.13 \%$ for primary haemorrhage, $5.37 \%$ for secondary haemorrhage, and $6.5 \%$ as overall for cold dissection with cold haemostasis; $0.99 \%$ for primary haemorrhage, $2.91 \%$ for secondary haemorrhage, and $3.9 \%$ as overall for cold dissection with hot haemostasis; $1.31 \%$ for primary haemorrhage, $7.38 \%$ for secondary haemorrhage, and $8.69 \%$ as overall for hot dissection with hot haemostasis. The statistical comparison did not show significant differences between the frequencies of post-tonsillectomy primary, secondary, and total haemorrhage in relation to the surgical techniques employed.

Conclusion: A great variability in the frequency of haemorrhagic complications reported in the selected articles was found, regardless of the surgical technique. These findings, together with the lack of a statistically significant difference in post-tonsillectomy haemorrhage between the techniques employed, must be carefully considered by professionals involved in health organizations in clinical wards and the relative problems linked to medical liability.
\end{abstract}

\section{Introduction}

Adenotonsillar disease and the surgical treatments reveal that this condition may still raise concerns leading to the formulation of several guidelines $[1,2]$, particularly in relation to potential post-operative complications [3]. Studies in literature present no uniform results regarding the general frequency of post-tonsillectomy haemorrhage [3] and the possible relationship between the type of surgical technique employed and the rate of haemorrhagic complications $[4,5]$.

Post-tonsillectomy bleeding represents one of the most feared complications and constitutes an important cause of medical-legal dispute in otolaryngologic field [6]. Recent national guidelines on the appropriateness of tonsillectomy [7], as well as the studies specifically devoted to the safety of surgical techniques in tonsillectomy [8-12], give particularly rigid addresses that appear to be in contrast with some clinical research data $[8,10,13,14]$ and that deserve a greater critical examination.

The present study has set out to verify the frequency of post-tonsillectomy haemorrhagic complications and the possible differences in post-tonsillectomy haemorrhage rate according to the most employed surgical techniques.

\section{Materials and Methods}

A MEDLINE inquiry was carried out using PubMed, Scopus, and Inter-Wiley as database, inserting the keywords "post-tonsillectomy haemorrhage" and "post-tonsillectomy bleeding", and restricting the research to the studies published between 2000 and 2015.

In total, 231 studies were identified. From these, the multi-centric English language papers were extrapolated, in which the three most commonly used dissection and haemostasis techniques [15] were analysed: cold dissection with cold haemostasis $(\mathrm{CD} / \mathrm{CH})$, in which the tonsillar dissection is achieved by the use of cold traditional instruments (scalpel, scissors, scaler) and the haemostasis is obtained by compression and ligature of blood vessels; cold dissection with hot haemostasis $(\mathrm{CD} / \mathrm{HH})$, in which the cold steel dissection is in combination with diathermy for haemostasis; hot dissection with hot haemostasis $(\mathrm{HD} / \mathrm{HH})$, in which the dissection and haemostasis are achieved by diathermy. The examined studies analysed such surgical techniques in relation to the percentage of post-surgical haemorrhage primary (occurring within the first 24 hours after surgery), secondary (occurring after 24 hours from surgery), and total, regardless of whether it had been necessary to return to the theatre to stop the bleeding. 
Eight studies were selected, relative to the three techniques under examination (Tables 1-3), excluding a multi-centric study [21] in English language, as only the total percentage of post-operative bleeding was reported, and including a multi-centric Italian study conducted in 15 centres between 2002 and 2008 and published in 2011 [19].

In Lowe et al.'s [10] paper, the data divided by the authors into two groups - before and after the guidance issued by the National Institute for Clinical Excellence/British Association of Otolaryngologist, Head and Neck Surgeons in 2004 [22] — were analysed with reference to the global series.

ANOVA test was used to compare the surgical techniques under study, considering $P<0.05$ as the minimum level of statistical significance. The data analysis was conducted using software R of the R Development Core Team, a free software distributed under the GNU GPL license.

\section{Results}

The data, relative to the post-operative haemorrhage are reported in Table 4. No significant differences were found in the frequency of the primary, secondary and total haemorrhage among the different surgical techniques employed (Table 5).

\section{Discussion}

Tonsillectomy is one of the most commonly performed surgical procedures $[23,24]$, although the scientific literature rarely provides the prevalence of tonsillectomy and adenotonsillectomy [25]. Some data are found for Denmark: approximately 7,000 annual tonsillectomies [26], Scotland: 14,530 (sum from 2002-2005) and 3,605 (sum from 2006-2007) [27], Sweden: about 10,000 procedures per year [28], England with Wales: 19,250 tonsillectomies per year [29], Italy: 44,000 (2000) [30], 59,916 (2002) and 51,983 (2003) [7], France: about 50,000 pediatric tonsillectomies each year [31], Great Britain: 78,000 (during 1994 and 1995) [32] and about 90,000 annual surgical procedures [33], and USA: 1,400,000 (1959), 500,000 (1979) [34], 286,000 (1994) [35,36] as well as 287,000 children (1996) [37] and 530,000 [38,39,1] and 250,000 annual pediatric tonsillectomy [40]. In Italy, the rate of tonsillectomy reported is of 10.7 (2000), 10.5 (2002), 9.1 (2003), and 9.4 (2004) per 10,000 inhabitants [41].

The continuing disagreement regarding the indication for tonsillectomy leads to different rates of this surgical procedure, both between nations [41,42] and within single countries [43].

The present study is focused on the three most commonly used techniques in tonsillectomy [44], namely, $\mathrm{CD} / \mathrm{CH}, \mathrm{CD} / \mathrm{HH}$ and $\mathrm{HD} / \mathrm{HH}$.

Previous studies suggest that the different surgical techniques for

Table 1. Frequency of Post-tonsillectomy Haemorrhage Relative to Cold Dissection With Cold Haemostasis

\begin{tabular}{|l|c|c|c|c|}
\hline \multicolumn{1}{|c|}{ Author } & No. of patients & $\begin{array}{c}\text { No. of primary } \\
\text { haemorrhage }\end{array}$ & $\begin{array}{c}\text { No. of secondary } \\
\text { haemorrage }\end{array}$ & $\begin{array}{c}\text { No. of total } \\
\text { haemorrhages }\end{array}$ \\
\hline Raut [16] & 92 & $17(18.47 \%)$ & 0 & $17(18.47 \%)$ \\
\hline Raut [17] & 32 & $1(3.13 \%)$ & $4(12.5 \%)$ & $5(15.62 \%)$ \\
\hline NPTA [9] & 1327 & $8(0.6 \%)$ & $10(0.75 \%)$ & $18(1.36 \%)$ \\
\hline Walker [14] & 13 & 0 & $1(7.69 \%)$ & $1(7.69 \%)$ \\
\hline Lowe [10] & 4279 & $35(0.82 \%)$ & $41(0.96 \%)$ & $76(1.78 \%)$ \\
\hline Tomkinson [18] & 6207 & $43(0.69 \%)$ & $17(0,27 \%)$ & $60(0.97 \%)$ \\
\hline Motta [19] & 5327 & $41(0.77 \%)$ & $29(0.54 \%)$ & $70(1.31 \%)$ \\
\hline Soderman [20] & 1164 & $35(3 \%)$ & $21(1.8 \%)$ & $56(4.81 \%)$ \\
\hline
\end{tabular}

Table 2. Frequency of Post-tonsillectomy Haemorrhage Relative to Cold Dissection with Hot Haemostasis

\begin{tabular}{|l|c|c|c|c|}
\multicolumn{1}{|c|}{ Author } & No. of patients & $\begin{array}{c}\text { No. of primary } \\
\text { haemorrhage }\end{array}$ & $\begin{array}{c}\text { No. of secondary } \\
\text { haemorrage }\end{array}$ & $\begin{array}{c}\text { No. of total } \\
\text { haemorrhages }\end{array}$ \\
\hline NPTA [9] & 4444 & $19(0.43 \%)$ & $108(2.43 \%)$ & $127(2.86 \%)$ \\
\hline Walker [14] & 480 & $1(0.21 \%)$ & $26(5.42 \%)$ & $27(5.63 \%)$ \\
\hline Lowe [10] & 13706 & $66(0.48 \%)$ & $173(1.26 \%)$ & $239(1.74 \%)$ \\
\hline Tomkinson [18] & 8506 & $64(0.75 \%)$ & $84(0.99 \%)$ & $148(1.74 \%)$ \\
\hline Motta [19] & 5697 & $36(0.63 \%)$ & $106(1.86 \%)$ & $142(2.50 \%)$ \\
\hline Soderman [20] & 10276 & $354(3.44 \%)$ & $566(5.51 \%)$ & $920(8.95 \%)$ \\
\hline
\end{tabular}

Table 3. Frequency of Post-tonsillectomy Haemorrhage Relative to Hot Dissection with Hot Haemostasis

\begin{tabular}{|l|c|c|c|c|}
\multicolumn{1}{|c|}{ Author } & No. of patients & $\begin{array}{c}\text { No. of primary } \\
\text { haemorrhage }\end{array}$ & $\begin{array}{c}\text { No. of secondary } \\
\text { haemorrage }\end{array}$ & $\begin{array}{c}\text { No. of total } \\
\text { haemorrhages }\end{array}$ \\
\hline Raut [16] & 91 & 0 & $14(15.38 \%)$ & $14(15.38 \%)$ \\
\hline Raut [17] & 18 & $1(5.55 \%)$ & $3(16.67 \%)$ & $4(22.22 \%)$ \\
\hline NPTA [9] & 4864 & $22(0.45 \%)$ & $178(3.66 \%)$ & $200(4.11 \%)$ \\
\hline Walker [14] & 618 & $2(0.32 \%)$ & $26(4.21 \%)$ & $28(4.53 \%)$ \\
\hline Lowe [10] & 12983 & $58(0.45 \%)$ & $291(2.24 \%)$ & $349(2.69 \%)$ \\
\hline Motta [19] & 2532 & $1(0.04 \%)$ & $61(2.41 \%)$ & $62(2.45 \%)$ \\
\hline Soderman [20] & 2470 & $58(2.35 \%)$ & $176(7.12 \%)$ & $234(9.47 \%)$ \\
\hline
\end{tabular}


Table 4. Average Percentage of Post-operative Haemorrhage

\begin{tabular}{|l|r|}
\hline \multicolumn{2}{|l|}{ Cold dissection with cold haemostasis } \\
\hline Primary Haemorrhage & $1.13 \%(0.012)$ \\
\hline Secondary Haemorrhage & $5.37 \%(0.068)$ \\
\hline Total Haemorrhages & $6.5 \%(0.069)$ \\
\hline Hot dissection with cold haemostasis & \\
\hline Primary Haemorrhage & $0.99 \%(0.012)$ \\
\hline Secondary Haemorrhage & $2.91 \%(0.020)$ \\
\hline Total Haemorrhages & $3.9 \%(0.028)$ \\
\hline Hot dissection with hot haemostasis & \\
\hline Primary Haemorrhage & $1.31 \%(0.020)$ \\
\hline Secondary Haemorrhage & $7.38 \%(0.061)$ \\
\hline Total Haemorrhages & $8.69 \%(0.075)$ \\
\hline
\end{tabular}

tonsillectomy have different impacts on post-operative mortality [45], even though no technique has ever been described as the "gold standard" [46].

Hot techniques remain as the most widespread techniques in many countries [9]. Hot dissection is used in about $50 \%$ of tonsillectomies [20] in Great Britain, whereas in Australia $64 \%$ of tonsillectomies are performed using various types of "hot" techniques [47]. An investigation carried out in the USA in 2011 indicated the mono-polar cauterization as the most common technique for haemostasis in tonsillectomy [48]. In Sweden, the majority of procedures are carried out by hot techniques, whereas the cold techniques are seldom used nowadays [9].

Mowatt et al. [8] reported a significantly lower frequency of primary haemorrhage in the subjects who underwent hot technique or cold dissection with hot haemostasis, whereas the frequency of secondary haemorrhage was higher in the subjects who underwent cold technique surgery, although not significant (the data was significant only when coblation was used).

Lowe et al. [9], in the "Prospective National Audit" for the National Health Service, conducted a survey involving 277 hospitals and including data related to 33,921 patients. The authors found haemorrhagic episodes more frequently in the subjects operated by the "hot" techniques.

The reliability of these data, however, has been questioned by the authors themselves for the imprecise definition of primary or secondary haemorrhage (e.g. haemorrhage that has onset in the first 24 hours sometimes extends beyond this temporal limit) or for the partial information supplied by the responders. The authors also noted that the higher frequency of post-operative haemorrhage in subjects operated by cold technique, but in which hot haemostasis was carried out, could depend on the energy "dosage" employed.

Hilton [49] underlines the advantages that diathermy offers (reduced bleeding during surgery; shortening of surgical time), but also points out that the risks are practically negligible; in fact, its use brings about an actual increase in the number of bleeding episodes of only $1-2 \%$.

However, haemorrhagic complications occur at very variable rates and are reported in the literature as between $0.3 \%$ and over $10 \%$ [41], independently of the surgical technique used; this could depend on a series of biases in the evaluation of the haemorrhagic event, amongst which we consider important to point out the following issues.

\section{Definition of Bleeding and Chronology of Haemorrhagic Complica-} tions

Many authors report only those haemorrhages that required second surgery, whilst the others report all the episodes of post-tonsillectomy bleeding [5]; thus, in the publications in which only the haemorrhages that needed surgical treatment are considered, the rate of post-tonsillec-
Table 5. Comparison Between the Frequency of Primary, Secondary and Total Post-operative Haemorrhage among the Different Surgical Techniques Employed

Primary haemorrhage

\begin{tabular}{l|c}
\hline General mean & $1.15 \%$ \\
\hline Deviation between groups & $3.340506 \mathrm{e}-05$ \\
\hline P-value & 0.9326776
\end{tabular}

Secondary haemorrhage

General mean

$5.34 \%$

Deviation between groups

0.0064643

P-value

0.3844713

Total haemorrhage

General mean

$6.49 \%$

Deviation between groups

0.007411413

P-value

0.41378063

tomy haemorrhage is lower, but mortality percentages rise, compared to those studies in which all haemorrhages are reported [50].

In this regard, Tomkinson [18], not only reports the incidence of primary and secondary post-surgical haemorrhage, but also distinguishes slight haemorrhagic complications (primary and secondary) from those that required second surgery, thus giving a more precise evaluation of the true risk of post-operative bleeding associated with the surgical technique employed. In the same way Soderman [20] reports the percentages of post-operative bleeding, also specifying the percentage of patients that required second surgery.

The lack of information on the time interval between surgery and the onset of the haemorrhage renders the differentiation between the primary and secondary bleeding unreliable [51].

\section{Definition of Surgical Technique and Role of the Surgeon}

Some studies [52-54] indicate the cold technique as the "gold standard" for dissection, but the technique used to achieve haemostasis is not reported, and therefore it is impossible to establish whether the cold technique was used alone or a hot haemostasis was performed.

In the present study, only those scientific publications were selected, in which both the dissection and haemostasis techniques were specified, and the primary haemorrhage was distinguished from the secondary one with an accurate chronology of the haemorrhagic event.

The greater frequency of haemorrhage in those subjects in which hot haemostasis was performed could have been due to heat damage caused by diathermy coagulation of the vessels responsible for intra-operative bleeding $[37,46]$. However, cold dissection, just as any potential sutures for haemostasis, must be carried out with an extreme caution in order to avoid vascular damage, which could lead to successive bleeding [54-57].

It is probable, therefore, that the skill and experience of the single surgeon represents an important factor in the origin of these events. In the Italian multi-centric study of 2011, Motta et al. [19,52,58] did not find any statistically significant difference regarding the frequency of the primary, secondary and total haemorrhage, in relation to the surgical techniques employed.

On the other hand, the authors noted that the rate of haemorrhage reported by some of the medical institutions that took part in the study was significantly higher for the same techniques used. In light of these results, the authors conclude that this variability can be attributed to possible errors in the individual behavior of the surgeon himself, rather than the kind of technique adopted.

\section{Age of Patient}

Michael et al. [12] in a study on 337 cases (145 operated by cold tech- 
nique, 192 by hot technique) observed a higher frequency of haemorrhage in the adults compared to the children, as confirmed by Mosges in a paper published in 2011 [59], according to which, the increased frequency of bleeding in adults could be due to variables independent of the surgical technique, such as the variability in compliance of patients with the post-operative instructions (post-surgical diet and physical rest), smoking, presence of comorbidity, conditions of the tonsils, and coagulation defects.

In this regard, Tomkinson et al. [18] underlined that in patients over 12 years of age, the risk of post-operative bleeding (primary or secondary) that required a surgical treatment was 1.5 to 3 times greater than the population of patients under 12 years of age.

This data is confirmed by Walker [14], who, in the evaluation of the frequency of post-tonsillectomy haemorrhage, observes how this increased in a statistically significant way above all for secondary haemorrhage in different groups of patients according to age, with a risk which ranges from $0.6 \%$ in the patients below 4 years of age to $10.1 \%$ in the patients over 18 years of age.

\section{Conclusion}

The present study does not demonstrate any significant difference in the primary, secondary and total haemorrhage frequency between the three surgical techniques studied, differently from other authors [8-12,24].

A considerably low frequency of haemorrhagic complications following tonsillectomy, with a notable difference between the studies, emerged from the publications examined. A wide variability in the rate of haemorrhage is generally verified, especially with regard to the hot techniques; this does not appear to be attributable to the technique employed, but to the other factors, amongst which, in our opinion, the most important are the experience of the surgeon and the modalities with which the diathermy of bleeding vessels is carried out.

These data and the results of similar and recent studies on this issue must be evaluated for the formulation of clinical recommendations regarding the choice of techniques to be used for tonsillectomy, and cause doubts on the value of the strict clinical recommendations regarding the choice of techniques to be used for tonsillectomy.

\section{Article Information}

*Correspondence: Domenico Testa, MD, PhD

Department of Anesthesiologic, Surgical and Emergency Sciences, Head and Neck Surgery Unit, University of Campania "Luigi Vanvitelli", Italy. E-mail: domenico.testa@unicampania.it

Received: Aug. 02, 2017; Accepted: Oct. 12, 2017; Published: Apr. 12, 2018

DOI: 10.24983/scitemed.aohns.2018.00057

Copyright $\odot 2018$ The Author(s). This is an open-access article distributed under the terms of the Creative Commons Attribution 4.0 International License (CC-BY)

\section{Funding: None}

\section{Conflict of Interest Disclosures: None}

\section{Keywords}

Tonsillectomy; post-tonsillectomy haemorrhage; post-tonsillectomy complications

\section{References}

1. Baugh RF, Archer SM, Mitchell RB, et al. Clinical practice guideline: tonsillectomy in children. Otolaryngology-Head and Neck Surgery 2011;144(1 Suppl):S1-S30.

2. Scottish Intercollegiate Guidelines Network. Management of sore throat and indications for tonsillectomy. A National Clinical Guideline. Edinburgh: SIGN Publication Number 34, 1999. Available at: http://www.sign.ac.uk/sign-117-management-of-sore-throat-andindications-for-tonsillectomy.html

3. Motta G, Motta S, Cassano P, et al. Effects of guidelines on adenotonsillar surgery on the clinical behavior of otorhinolaryngologists in Italy. BMC Ear, Nose \& Throat Disorders 2013;13:1.

4. Sarny S, Ossimitz G, Habermann W, Stammberger H. Austrian tonsil study part 3: surgical technique and postoperative hemorrhage after tonsillectomy. Laryngorhinootologie 2013;92:92-96.

5. Mösges R, Hellmich M, Allekotte S, Albrecht K, Böhm M. Hemorrhage rate after coblationtonsillectomy: a meta-analysis of published trials. European Archives of Oto-Rhino-Laryngology 2011;268:807-816.

6. Polistena A, Di Lorenzo P, Sanguinetti A, et al. Medicolegal implications of surgical errors and complications in neck surgery: a review based on the Italian current legislation. Open Medicine (Poland) 2016:11:298-306.

7. National Guideline System (SNLG), Italian National Institute of Health (ISS). Appropriateness and safety of tonsillectomy and/or adenoidectomy - 2008. Available at: http://www.snlg-iss.it/en_lgn_tonsillectomy_2008

8. Mowatt G, Cook JA, Fraser C, McKerrow WS, Burr JM. Systematic review of the safety of electrosurgery for tonsillectomy. Clinical Otolaryngology 2006;31:95-102.

9. Lowe D, van der Meulen J, National Prospective Tonsillectomy Audit. Tonsillectomy technique as a risk factor for postoperative hemorrhage. Lancet 2004;364:697-702.

10. Lowe D, van der Meulen J, Cromwell D, et al. Key messages from the national prospective tonsillectomy audit. Laryngoscope 2007;117:717-724.

11. Haddow K, Montague ML, Hussain SS. Post-tonsillectomy hemorrhage: a prospective, randomized, controlled clinical trial of cold dissection versus bipolar diathermy dissection. The Journal of Laryngology Otology 2006;120:450-454.

12. Lee MS, Montague ML, Hussain SS. Post-tonsillectomy hemorrhage: cold versus hot dissection. Otolaryngology-Head and Neck Surgery 2004;131:833-836.

13. Brown PM. How safe is paediatric tonsillectomy? International Journal of Pediatric Otorhinolaryngology 2006;70:575-577.

14. Walker P, Gilles D. Post-tonsillectomy hemorrhage rates: are they technique-dependent? Otolaryngology-Head and Neck Surgery 2007;136(4 Suppl):S27-S31.

15. Carney AS, Harris PK, MacFarlane PL, Nasser S, Esterman A. The coblation tonsillectomy learning curve. Otolaryngology-Head and Neck Surgery 2008;138(2):149-152.

16. Raut V, Bhat N, Kinsella J, Toner JG, Sinnathuray AR, Stevenson M. Bipolar scissors versus cold dissection tonsillectomy; a prospective, randomized, multi-unit study. Laryngoscope 2001;111:2178-2182.

17. Raut V, Bhat N, Sinnathuray AR, Kinsella JB, Stevenson M, Toner JG. Bipolar scissors versus cold dissection for pediatric tonsillectomy: a prospective, randomized pilot study. International Journal of Pediatric Otorhinolaryngology 2002;64:9-15.

18. Tomkinson A, Harrison W, Owens D, Harris S, McClure V, Temple M. Risk factors for postoperative hemorrhage following tonsillectomy. Laryngoscope 2011:121;279-288.

19. Motta G, Motta S, Cassano $P$, et al. A mulicentric study on guidelines and (adeno)-tonsillectomy. Acta Otorhinolaryngologica Italica (Argomenti) 2011;5:1-32. Available at: http://www.actaitalica.it

20. Söderman AC, Odhagen E, Ericsson E, et al. Post-tonsillectomy haemorrhage rates are related to technique for dissection and for haemostasis. An analysis of 15734 patients in the National Tonsil Surgery Register in Sweden. Clinical Otolaryngology 2015;40:248-254.

21. Sarny S, Ossimitz G, Habermann W, Stammberger H. Hemorrhage following tonsil surgery: a multicenter prospective study. Laryngoscope 2011;121:2553-2560. 
22. The National Institute for Health and Care Excellence. Interim guidance on the use of diathermy in tonsillectomy. 2004. Available at: https://www.nice.org.uk/

23. Macarone Palmieri A, Testa D, Salafia M, Meglio M, Capaldo A. II vomito post-operatorio nell'intervento di adenotonsillecomia in pazienti pediatrici. L'Otorinolaringologia Pediatrica 1996;7:3-4. Available at: https://iris.unicampania.it/handle/11591/198158

24. Darrow $\mathrm{DH}$, Siemens C. Indications for tonsillectomy and adenoidectomy. Laryngoscope 2002;112:6-10.

25. Windfuhr JP. Specified data for tonsil surgery in Germany. GMS Current Topics in Otorhinolaryngology, Head and Neck Surgery 2016;15.

26. Ovesen T, Kamarauskas G, Dahl M, Mainz J. Pain and bleeding are the main determinants of unscheduled contacts after outpatient tonsillectomy. Danish Medical Journal 2012;59:A4382.

27. Management of sore throat and indications for tonsillectomy. A national clinical guideline. Edinburgh: Scottish Intercollegiate Guidelines Network 2010. Available at: http://www.sign.ac.uk/pdf/ sign117.pdf

28. Hessén Söderman AC, Ericsson E, Hemlin C, et al. Reduced risk of primary postoperative hemorrhage after tonsil surgery in Sweden: results from the National Tonsil Surgery Register in Sweden covering more than 10 years and 54,696 operations. Laryngoscope 2011;121:2322-2326.

29. Stafford N, von Haacke N, Sene A, Croft C. The treatment of recurrent tonsillitis in adults. The Journal of Laryngology and Otology 1986;100:175-177.

30. Materia E, Baglio G, Bellussi L, et al. The clinical and organisational appropriateness of tonsillectomy and adenoidectomy-an Italian perspective. International Journal of Pediatric Otorhinolaryngology 2005;69:497-500.

31. Lescanne E, Chiron B, Constant I, et al. Pediatric tonsillectomy: clinical practice guidelines. European Annals of Otorhinolaryngology Head and Neck Diseases 2012;129:264-271.

32. Marshall T. A review of tonsillectomy for recurrent throat infection. British Journal of General Practice 1998;48:1331-1335.

33. Lock C, Wilson J, Steen N, et al. North of England and Scotland Study of Tonsillectomy and Adeno-tonsillectomy in Children (NESSTAC): a pragmatic randomized controlled trial with a parallel non-randomised preference study. Health Technology Assessment 2010;14:1-164,iii-iv.

34. Rosenfeld RM, Green RP. Tonsillectomy and adenoidectomy: changing trends. The Annals of Otology, Rhinology and Laryngology 1990;99(3 Pt 1):187-191.

35. Paradise JL, Bluestone CD, Colborn DK, et al. Adenoidectomy and adenotonsillectomy for recurrent acute otitis media: parallel randomized clinical trials in children not previously treated with tympanostomy tubes. JAMA 1999;282:945-953.

36. Hall MJ, Kozak LJ, Gillum BS. National survey of ambulatory surgery: 1994. Statistical Bulletin Metropolitan Life Insurance Company 1997;78:18-27.

37. Paradise JL, Bluestone CD, Colborn DK, Bernard BS, Rockette HE, Kurs-Lasky M. Tonsillectomy and adenotonsillectomy for recurrent throat infection in moderately affected children. Pediatrics 2002;110 (1 pt 1):7-15.

38. Oomen KP, Modi VK, Stewart MG. Evidence-based practice: pediatric tonsillectomy. Otolaryngologic Clinics of North America 2012;45:10711081.

39. Ramos SD, Mukerji S, Pine HS. Tonsillectomy and adenoidectomy. Pediatric Clinics of North America 2013;60:793-807.
40. Friedman M, Wilson M, Lin HC, Chang HW. Updated systematic review of tonsillectomy and adenoidectomy for treatment of pediatric obstructive sleep apnea/hypopnea syndrome. Otolaryngology Head and Neck Surgery 2009;140:800-808.

41. Bellussi LM, Marchisio P, Materia E, Passàli FM. Clinical guideline on adenotonsillectomy: the Italian experience. Advances in Oto-Rhino-Laryngology 2011;72:142-145.

42. Van Den Akker EH, Hoes AW, Burton MJ, Schilder AG. Large international differences in (adeno) tonsillectomy rates. Clinical Otolaryngology and Allied Sciences 2004;29:161-164.

43. Stockwell H, Vayda E. Variations in Surgery in Ontario. Medical Care 1979;17:390-396.

44. Materia E, Di Domenicantonio R, Baglio G, et al. Epidemiology of tonsillectomy and/or adenoidectomy in Italy. La Pediatria Medica e Chirurgica 2004;26:179-186.

45. Mink JW, Shaha SH, Brodsky L. Making sense out of tonsillectomy literature. International Journal of Pediatric Otorhinolaryngology 2009;73:1499-1506.

46. Windfuhr JP, Wienke A, Chen YS. Electrosurgery as a risk factor for secondary post-tonsillectomy hemorrhage. European Archives of Oto-Rhino-Laryngology 2009;266:111-116.

47. Macfarlane PL, Nasser S, Coman WB, Kiss G, Harris PK, Carney AS. Tonsillectomy in Australia: an audit of surgical technique and postoperative care. Otolaryngology-Head and Neck Surgery 2008;139:109114.

48. Setabutr D, Adil EA, Adil TK, Carr MM. Emerging trends in tonsillectomy. Otolaryngology-Head and Neck Surgery 2011;145:223-229.

49. Hilton M. Tonsillectomy technique-tradition versus technology. Lancet 2004;364:642-643.

50. Liu JH, Anderson KE, Willging JP, et al. Post tonsillectomy hemorrhage: what is it and what should be recorder? Archives of Otolaryngology Head and Neck Surgery 2001;127:1271-1275.

51. Blakley BW. Post-tonsillectomy bleeding: how much is too much? Otolaryngology-Head and Neck Surgery 2009;140:288-290.

52. Blanchford H, Lowe D. Cold versus hot tonsillectomy: state of the art and recommendations. ORL: Journal for Oto-Rhino-Laryngology and Related Specialties 2013;75:136-141.

53. Motta G, Esposito E, Motta S, et al. Surgical treatment of acute recurrent throat infections in children. Auris, Nasus, Larynx 2011;38:356361.

54. Burton MJ, Doree C. Coblation versus other surgical techniques for tonsillectomy. The Cochrane Database of Systematic Reviews 2007;18:CD004619.

55. Nathan MD, Sessions DG. Massive posttonsillectomy hemorrhage. Southern Medical Journal 1981;74:1153-1156.

56. Gardner JF. Sutures and disasters in tonsillectomy. Archives of Otolaryngology 1968;88:551-555.

57. Macarone Palmieri A, Meglio M, Testa D, Salafia M, Iasiello A. Anesthesiologic and surgical problems in adenotonsillectomy in pediatric patients. Our current trend. Minerva Anestesiologica 1998;64:545552.

58. Motta G, Esposito E, Motta S, et al. Acute recurrent pharyngonsillitis and otitis media. Acta Otorhinolaryngologica Italica 2006;26(5 Suppl 84):30-55.

59. Mosges R, Hellmich M, Allekotte S. Hemorrhage rate after coblation tonsillectomy. A meta-analysis of published trials. European Archives of Oto-Rhino-Laryngology 2011;68:807-816. 